\title{
SUSPENDED RECTANGULAR/CIRCULAR PATCH ANTENNAS WITH ELECTROMAGNETICALLY COUPLED INVERTED MICROSTRIP FEED FOR DUAL POLARIZATION/FREQUENCY
}

\author{
Rainee N. Simons* \\ NASA Glenn Research Center, Dynacs Engineering Company, Inc. \\ 21000 Brookpark Road, Cleveland, Ohio 44135
}

\begin{abstract}
The paper demonstrates suspended rectangular and circular patch antennas with elctromagnetically coupled inverted microstrip feed for linear as well as dual linear polarization/frequency applications. The measured results include the return loss and the impedance bandwidth of the antennas.
\end{abstract}

\section{INTRODUCTION}

Future space borne microwave/millimeter-wave systems for Earth observation will require antennas which have high gain, high efficiency, low profile, light weight and low cost. At millimeter-wave frequencies conventional microstrip lines suffer from high conductor loss [1], [2]. The high conductor loss impacts the gain and the efficiency of an array antenna with corporate feed. The conductor loss can be reduced by constructing the feed network using low loss transmission media such as, inverted microstrip [1], [2], suspended microstrip [3] and suspended substrate stripline [4]. A suspended patch antenna excited by an electromagnetically coupled inverted microstrip feed at S-Band frequency has been demonstrated in [5]. In this paper first, suspended rectangular and also circular patch antennas with electromagnetically coupled inverted microstrip feed for linear polarization is demonstrated at K-Band frequencies. Second, suspended rectangular patch antenna and also circular patch antenna with segments removed for dual linear polarization/frequency is demonstrated at $\mathrm{Ku} / \mathrm{K}$-Bands. These antennas have two orthogonal inverted microstrip feeds and are electromagnetically coupled to the patches. The advantages of the above feeding technique include significantly lower attenuation and easier fabrication due to wider strip width for a given characteristic impedance $\left(Z_{0}\right)[6]$. The measured results include the return loss and the impedance bandwidth of the antennas.

\section{ANTENNA CONSTRUCTION}

An inverted microstrip line consists of a thin dielectric substrate (RT/duroid $\left.5880, \varepsilon_{\mathrm{r}}=2.22\right)$ of thickness $\mathrm{h}$ ( 0.01 inch) separated from a ground plane by an air gap of height $g\left(0.01\right.$ inch) as shown in Figure 1 . The strip conductor of width $W_{i}(\approx 0.045$ inch for $Z_{0}=50 \Omega$ ) is situated on the lower surface of the dielectric substrate facing the ground plane. A schematic of a rectangular patch antenna electromagnetically coupled to an inverted microstrip feed for linear polarization is shown in Figure 2. The length and width of the patch are $L$ and $W$ respectively. The inset in Figure 2 shows a circular patch antenna of radius $r$ with similar excitation. The overlap between the patch antennas and their feed line is indicated as S. Next, a rectangular patch antenna electro-magnetically coupled to two inverted microstrip line feeds for dual linear polarization/frequency is schematically illustrated in Figure 3. The inset in Figure 3 shows a circular patch antenna with segments $\Delta r$ removed and with similar excitation. The overlap between the patch antennas and their dual feeds are indicated as $S_{1}$ and $S_{2}$ respectively. 


\section{EXPERIMENTAL RESULTS}

The measured return loss of the rectangular and the circular patch antennas are shown in Figures 4 and 5 respectively. The measurements show that the antennas are very well matched to the $50 \Omega$ feed lines and the $-10.0 \mathrm{~dB}$ return loss bandwidths are about 3.65 and 6.38 percent respectively at $\mathrm{K}$-Band frequencies. Both antennas radiate with a linear polarization parallel to the feed. The measured return loss of the rectangular patch antenna with two orthogonal feeds for the vertical and horizontal polarizations are shown in Figures 6(a) and 6(b) respectively. The measurements show that the antennas are very well matched to the $50 \Omega$ feed lines and the $-10.0 \mathrm{~dB}$ return loss bandwidth for both polarizations is about 4.34 percent at $\mathrm{Ku} / \mathrm{K}$-Band frequencies. A similar set of measurements for the circular patch antenna with the segments removed is shown in Figures 7 (a) and $7(\mathrm{~b})$ respectively. The $-10.0 \mathrm{~dB}$ return loss bandwidth is about 8.9 percent at K-Band frequencies. The radiation pattern measurements of the antennas are in progress.

\section{CONCLUSIONS}

The paper demonstrates a suspended rectangular and also circular patch antennas with electromagnetically coupled inverted microstrip feed first, for linear polarization and second, for dual linear polarizations/frequency operation at $\mathrm{Ku} / \mathrm{K}-\mathrm{B}$ and frequencies. The measured results include the return loss and the impedance bandwidth of the antennas.

\section{References}

[1] T. Itoh, "Overview of Quasi-Planar Transmission Lines," IEEE Trans. Microwave Theory Tech., vol. 37, no. 2, pp. 275-280, February 1989.

[2] B.E. Spielman, "Dissipation Loss Effects in Isolated and Coupled Transmission Lines," IEEE Trans. Microwave Theory Tech., vol. MTT-25, no. 8, pp. 648-656, August 1977.

[3] J.M. Baracco and A. Carlstrom, "X-Band Microstrip Array Antenna in Suspended Technology," 1997 IEEE Antennas and Propagation Society Inter. Symp. Dig., vol. 2, pp. 1256-1259, 1997.

[4] E. Rammos, "A Low Tolerance Dual Slot Radiator for Space and Ground Applications," 1991 IEEE Antennas and Propagation Society Inter. Symp. Dig., vol. 3, pp. 1599-1602, 1991.

[5] Q. Zhang, Y. Fukuoka, and T. Itoh, "Analysis of a Suspended Patch Antenna Excited by an Electromagnetically Coupled Inverted Microstrip Feed," IEEE Trans. Antennas and Propagation, vol. AP-33, no. 8, pp. 895-899, August 1985.

[6] J. Rivera and T. Itoh, "Analysis of an Electromagnetically Coupled Patch Antenna," 1983 IEEE Antennas and Propagation Society Inter. Symp. Dig., vol. 1, pp. 170-173, 1983.

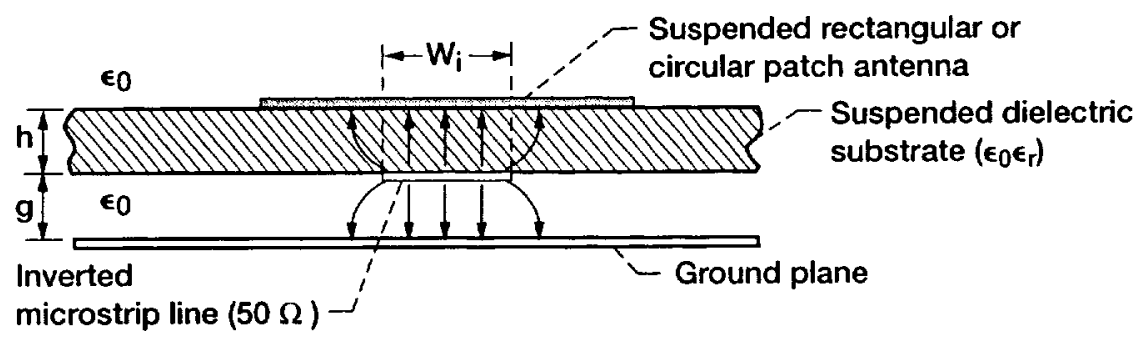

Figure 1.-Cross-section showing a suspended patch antenna excited by an inverted microstrip line feed. 


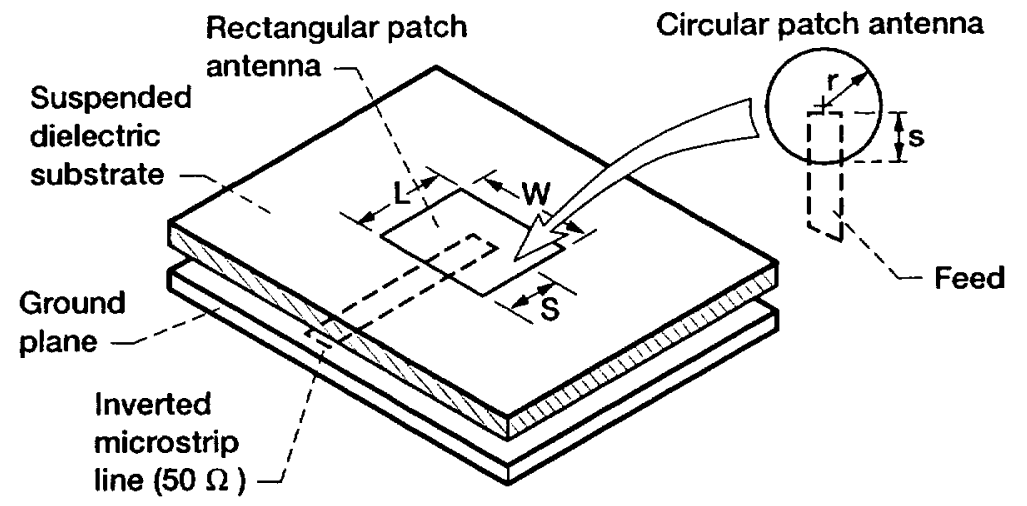

Figure 2.-Schematic of a rectangular patch antenna electromagnetically coupled to an inverted microstrip line feed for linear polarization. Inset shows the geometry of a circular patch antenna for a similar experiment. Dimensions in inches are rectangular: $L=0.206, W=0.232, S=0.083$, circular: $r=0.255, s=0.145$.

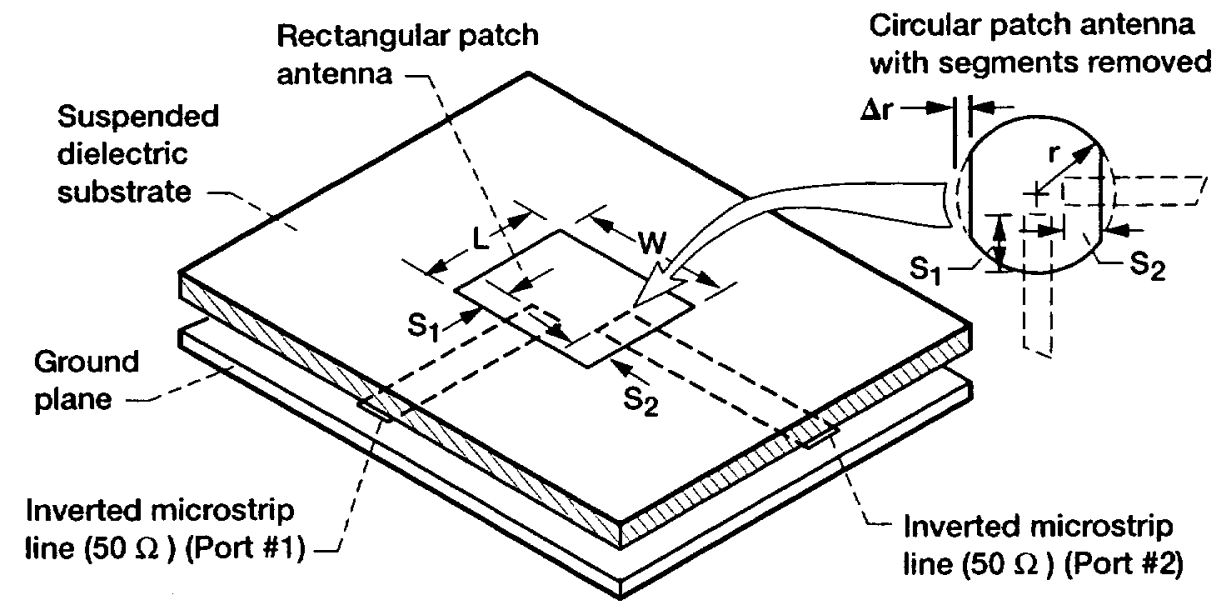

Figure 3.-Schematic of a rectangular patch antenna electromagnetically coupled to two inverted microstrip line feeds for dual linear polarization and frequency. Inset shows the geometry of a circular patch antenna with segments removed for a similar experiment. Dimensions in inches are rectangular: $L=0.225$, $\mathrm{W}=0.2685, \mathrm{~S}_{1}=0.097, \mathrm{~S}_{2}=0.094$, circular: $r=0.255, \Delta r=0.0125, \mathrm{~S}_{1}=0.0325$, $S_{2}=0.013$. 


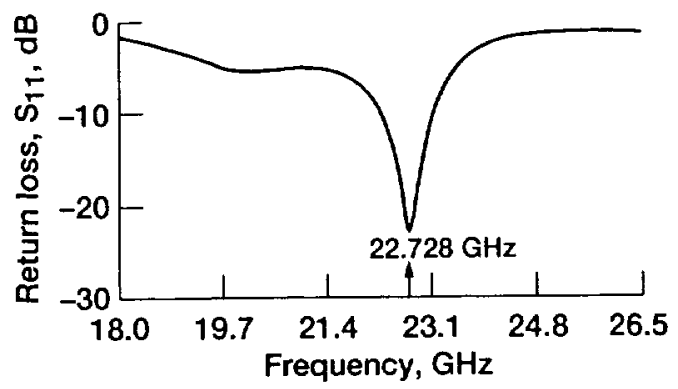

Figure 4.-Measured return loss of the rectangular patch antenna with single feed.
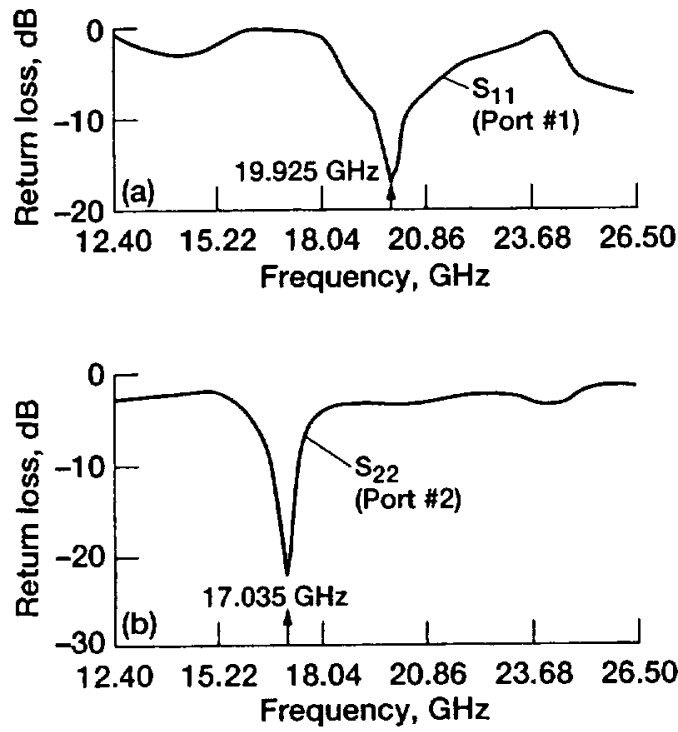

Figure 6.-Measured return loss of the rectangular patch antenna with two orthogonal feeds. (a) Vertical polarization. (b) Horizontal polarization.

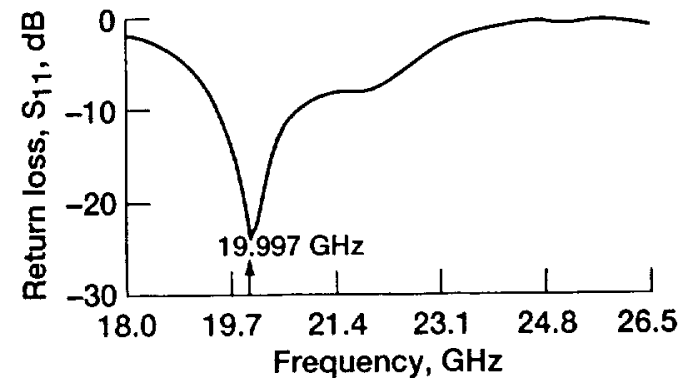

Figure 5.-Measured return loss of the circular patch antenna with single feed.
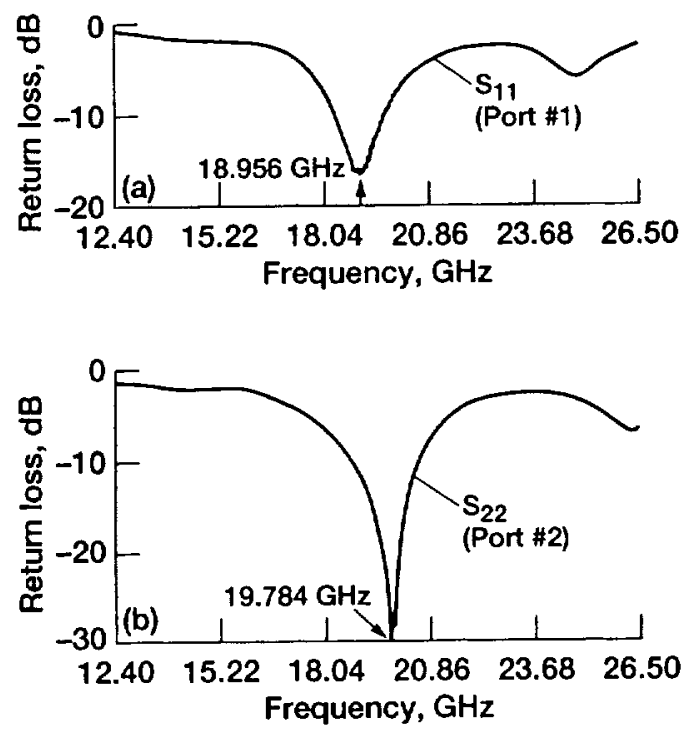

Figure 7.-Measured return loss of the circular patch antenna with segments removed and with two orthogonal feeds. (a) Vertical polarization. (b) Horizontal polarization. 